\title{
Musical Phenomenology: Artistic Traditions and Everyday Experience
}

\author{
Małgorzata A. Szyszkowska \\ Institute of Philosophy \\ University of Warsaw \\ m.a.szyszkowska@uw.edu.pl
}

Received 1 February 2018; accepted 14 May 2018; published 30 September 2018.

\begin{abstract}
The work begins by asking the questions of how contemporary phenomenology is concerned with music, and how phenomenological descriptions of music and musical experiences are helpful in grasping the concreteness of these experiences. I then proceed with minor findings from phenomenological authorities, who seem to somehow need music to explain their phenomenology. From Maurice Merleau-Ponty to Jean-Luc Nancy and back to Edmund Husserl and Martin Heidegger, there are musical findings to be asserted. I propose to look at phenomenological studies of the musical aspects of existence as they appear in various philosophical works bringing together different accounts of music and aesthetics and pointing towards phenomenological study as a methodology for everyday aesthetics.

While there are many different areas of music phenomenology such as studies of sound and listening, studies in perception of musical works, in experience of artistic creation, in singing and playing musical instruments, and phenomenology of transcendent or religious horizons of the experience of music, it is most promising - I suggest - to look at phenomenological studies of music from the perspective of everyday happenings and discoveries of musical aspects of life. Thus, I attempt to display the uses of phenomenology in finding musical aspects of everyday existence as well as in describing and illuminating the art of music. A look at Roman Ingarden's and Mikel Dufrenne's most intuitive and promising ideas will be broadened with a perspective from Don Ihde and Arnold Berleant.
\end{abstract}

Keywords: aesthetic experience; music; music phenomenology; phenomenological aesthetics. 


\section{Introduction}

Phenomenology has always been preoccupied with art. Painting and literature especially have been featured in many phenomenological accounts of experience used to describe the way the world appears and the way its meaning is shaped in and through experience. In the text "The Phenomenological Relevance of Art," Mark Wrathall (2011) maintains that phenomenology in general and specifically the traditions developed by Heidegger, Merleau-Ponty, Sartre, and Dufrenne take works of art to be capable "of showing us the phenomena under consideration more directly, powerfully, and perspicuously than any philosophical prose could" (Wrathall, 2011, p. 9).

It is easy to see the relevance of art in general for phenomenology, but it is less certain that music is a favorite phenomenological topic as well. The term musical phenomenology does not pop up often in philosophical literature. Is there a phenomenology of music to speak of? How is phenomenology concerned with music? Are phenomenological studies of music and musical experiences helpful in grasping the concreteness of everyday experiences? After all, music is an everyday item, or as Arnold Berleant put it, "aesthetic theory and musical practice do not inhabit entirely different worlds" (1999, p. 73). Music is also a highly developed artistic performance practice requiring many years of study. Music seems to be the kind of phenomena that should get the attention of phenomenology, perhaps not simply because of its being a developed artistic practice but because of its primary nature - as a process and an experience. In experiencing music, recipients discover not only the work but the process of development itself. However, if one asks how phenomenology is concerned with music the simple answer would be that it isn't. Music is scarcely mentioned in the phenomenological works of the authors mentioned above, with the exception of Dufrenne, and it has not been considered a domain of great philosophical interest. Even where music is, as it seems, the studied phenomenon, it is always considered from the point of view of its temporal nature. Still, the assumed temporality of music may be understood very differently. The temporal character of music is, as was shown by Roman Ingarden, at least double: it is either experienced in accordance with physical measurements which seem objectively present, or it is experienced purely subjectively as inner time or quasi-time (Ingarden, 1986).

Yet, at the same time, there is plenty of music in phenomenological writings. Despite a lack of direct references to music as art, phenomenological writers somehow find music well suited to explaining the areas most vital for phenomenology. From Maurice MerleauPonty to Jean-François Lyotard and back to Edmund Husserl and Martin Heidegger, there are musical findings to be asserted. There may not be a phenomenology of music in the sense of studies devoted to music and its artistic and aesthetics aspects, yet there are a lot of musical references in phenomenological writing, even though many of them are not concerned with art at all. I would like to address this apparent inconsistency in more detail.

Let me propose a division into three distinct areas or three ways in which music is featured within phenomenological studies: (1) the most general references to music, sometimes without its name being used, where music is surprisingly used for explaining the most 
important elements of phenomenological experience; (2) the phenomenological studies of music as artistic practice and studies of aesthetic experiences of music, and lastly (3) the area of phenomenological approach to auditory experiences and listening itself. This provisional and rough division is meant to show different ways in which music and references to music can be asserted and analyzed. My aim is not to claim that music is omnipresent or even that it plays an important part in any phenomenological writings. I would like to suggest instead that despite appearances, music and musical references may be found throughout phenomenological texts because of the way music is present, the way it is experienced - as a way of perceiving and as a process. And perhaps phenomenology of music has more to do with the way some writers choose to describe the world than with referring to music in general. Hopefully future studies will show many more ways in which the experiences of music are significantly present within phenomenology.

\section{Music as Phenomenology: Everyday Experience, Perception, and Meaning}

Perhaps the most curious and also the most valuable presence of music within phenomenology may be found in the philosophical works of Husserl and Heidegger, where it is not music as such but anything that is particularly musical (that is, sound, rhythm, time fluctuation, process, development, etc.) that is used for explaining phenomena of everyday experience and their meaning. It might seem a bit of a stretch to call this reference to music "music phenomenology," but in many ways, that's what it is. Music, when it is present in phenomenological writings, is used to stress certain aspects of an experience or perception. It is used precisely because - as a process, an event, an experience - it shows the important aspects of the experiencing itself.

Let me start with Edmund Husserl, who uses sequences of sounds as an example of an experience of time and continuity in his lectures on the phenomenology of inner consciousness of time (1991). This is perhaps the most obvious reference to music, even though the term "music" almost never appears in the text. In this particular excerpt, Husserl points to a sequence of sounds and writes, "I am conscious of the sound and the duration which it fills with continuity of 'modes' in a continuous 'flux"' (1964/1991, p. 44). And a bit further:

The same sound which is heard now is, from the point of view of the flux of consciousness that follows it, past, its duration expired. [...] Its temporal point is unmoved, but the sound vanished into the remoteness of consciousness; the distance from the generative now becomes even greater. (Husserl, 1964/1991, p. 45)

Husserl follows the sound as it appears in the consciousness of the listener-present and lasting, yet still moving and changing its appearance in the process. It moves from being present in the "now" to "sinking" into retention (Husserl, 1964/1991, p. 44). Husserl talks of sounds, yet, for the most part, what he really means is a sequence of sounds bound together through a musical affinity — a musical phrase or a melody. As it is only in melody, 
a part of the greater whole with intervallic and rhythmic structure, that listeners can truly assess the changes in the movement of sound. A sound itself (a sound wave) does not move or follow another sound. It spreads out evenly creating sound space. But Husserl discusses time, movement, and continuity in perception of sound. And again, sound as perceived does not form a sequential string it is an individual as much as the time it occupies (the sum of its reverberation), and it will not necessarily be retained in memory - why would it be? However, sounds in sequence, and thus a melody or music in general, are perceived as linked together and as following or fleeing from one another. A musical sequence is often described as sounds coming and going, one after the other, in relations of not only distance and presence, as illustrated by Husserl, but also in tonal (up and down) and harmonic (consonant or dissonant) relationships. The perception of sounds as discussed by Husserl doesn't merely present the way listeners apprehend sense data; it captures the very reality of perception as filled with sense qualities and data already in relation to one another (Husserl, 1991, p. 54). Therefore, music is used throughout Husserl's lectures to represent perception of time. In fact, the whole lecture concerning the phenomenology of internal time consciousness may be seen as based on a description of experiencing a musical sequence of sounds and its duration (1991, pp. 44, 54, 65).

In discussing secondary remembrance and the difference between perceiving and remembering, Husserl discusses melody openly. Remembering - Husserl claims - works in the same way as perception itself. It has a focus, the now-point, and in following each sound, past sounds are retained in memory (1964/1991, pp. 57-58). Perception of a melody relays changes from the sounds that are present to the sounds that are past. In perception the melody sounds as long as the last sound belonging to it (1991, p. 61). In this way, let me point out, music is often times used for doing philosophy without being acknowledged in this role.

In Martin Heidegger's philosophy, references to music may be discovered under references to its perceived aspects such as time, sound, "sounding," and special distribution of perceived data. His description of listening as preparation for speech and communication, as much as his description of factuality, reminds us about the very nature of experiencing music in listening, being open and being present:

Listening to [...] is Dasein's existential way of Being-open as Being-with for Others. Indeed, hearing constitutes the primary and authentic way in which Dasein is open for its own most potentiality-for-Being — as in hearing the voice of the friend. (Heidegger, 1927/1962, p. 206)

Heidegger describes listening to music, experiencing the music, but he seems less concerned with music than with listening. It is listening as one of the simple, primary ways of engaging with the world that is being described and pointed to. Yet, in this he points to the fact that music, as much as it consists in listening, is, as an experience, a primary and vastly important one. It turns out that humming to oneself or singing simple tunes is part of everyday experience just as walking or talking are. Here one finds Heidegger in an unlikely alliance with Wittgenstein, whose understanding of simple behavior included music in every form and shade. Still, the experience Heidegger is describing is that of finding oneself or being present, and music is simply found handy in helping to complete this description. 
In the writings of Maurice Merleau-Ponty, a similar situation may be found. It is in painting that that philosopher finds his perfect sensory example of the everyday experiencefluctuating outside of assumed shapes and "known" vistas. Yet music finds its way into the description of the experience. It is as if music and musical vocabulary were useful or even necessary to make the point, even though, as an artistic phenomenon, music is found all too abstract or too focused on itself.

In his lecture on "Art and the World of Perception," Merleau-Ponty declares that "music offers too straightforward an example and, for this reason, we shall not dwell on it for long here" (1948/2004, p. 99). Yet, a bit further he maintains:

From among these sounds we discern the appearance of a phrase and, as phrase follows phrase, a whole and, finally, as Proust put it, a world. This world exists in the universe of possible music, whether in the district of Debussy or the kingdom of Bach. All I have to do here is listen without soul-searching, ignoring my memories and feelings and indeed the composer of the work, to listen just as perception looks at the things themselves. (Merleau-Ponty, 1948/2004, pp. 99-100)

Listening to music is similar to perception in its wideness and far reaching openness. Musical references are also found in Merleau-Ponty's Phenomenology of Perception (1945/2012), especially in the author's attempt to show the intricate connection between meaning and meaningful objects. The most famous example might be this one:

The musical signification of a sonata is inseparable from the sounds that carry it; prior to having heard it no analysis enables us to anticipate it; once the performance has come to an end, we cannot do anything in our intellectual analysis of the music but refer back to the moment of the experience. During the performance, the sounds are not merely the "signs" of a sonata, rather, the sonata is there through them and descends into them. (Merleau-Ponty, $1945 / 2012$, p. 188)

In Phenomenology of Perception, Merleau-Ponty finds many ways to use music as an example: instances of the sensuous, examples of direct experiencing and understanding through immediate bodily response, or examples of expressive power. He uses melody as an analogy to the functioning of an organism in The Structure of Behavior (1942/1967) “the activity of the organism would be 'literally' comparable to a kinetic melody since any change in the end of the melody qualitatively modifies its beginning and the physiognomy of the whole" (Merleau-Ponty, 1942/1967, p. 107). Elsewhere in the same text, MerleauPonty says:

"Every organism" said Uexkull, "is a melody, which sings itself." This is not to say it knows the melody and attempts to realize it; it is only to say that it is a whole which is significant for a consciousness which knows it, not a thing which rests in-itself (en soi). (1942/1967, p. 159)

Musical metaphor seems to be the best way to put forward an understanding of the world in experience or, as Merleau-Ponty says, "the world as it is in our life and to our body" (1964, p. 57), which means, Mark Wrathall suggests, "everyday, ordinary, unreflective, practical engagement with the things around us" (Wrathall, 2011, p. 17). For MerleauPonty musical elements in aesthetic perception or musical practice bring perception of 
everyday experience to the fore; they are also excellent models for an organic collaboration of human mind and body, various extensions of the body, and many other things. In this particular example, he refers to musical practice for explaining the possibility of internal, inherent communication. "The character of the melody, the graphic configuration of the musical text and the unfolding of the gestures participate in a single structure, have in common a single nucleus of signification" (Merleau-Ponty, 1942/1967, p. 121). And again, for showing the different way in which we world is understood or grasped, he uses a comparison to musical work, again a symphony:

The world, in those of its sectors, which realize a structure, is comparable to a symphony, and knowledge of the world is thus accessible by two paths: one can note the correspondence of the notes played at a same moment by the different instruments and the succession of those played by each one of them. (Merleau-Ponty, 1942/1967, p. 132)

Here Merleau-Ponty uses references to musical practice and the art of music abundantly. Perhaps it shouldn't be surprising. After all, music is everywhere and everyone listens to it. Yet in his analysis, Merleau-Ponty is not concerned with music as such, his remarks are also not illuminative or revealing; rather it seems that music as a phenomenon has so many organic features and offers such clear insight into other processes that it would be silly not to turn to it. Still, it is remarkable that music is used as a reference point for understanding so many aspects of human behavior and its inner structures. Perhaps, as Jessica Wiskus suggests in her book The Rhythm of Thought: Art, Literature, and Music after MerleauPonty (2013), the musical is for Merleau-Ponty, by way of reading Proust and thus mediated through literature, pointing to immaterial reality as the reality one strives for and especially the reality of ideas. It is a model for intellectual experiences, which are themselves impenetrable, transparent in their shadowy presence and will never be experienced differently. But more than this, "it brings about transformation" (Wiskus, 2013, p. 94). As much as musical idea seems important for the evolution of characters in Proust, it is but one way of outlining the corporeal presence that music elitics so well. It renders visible, or rather it brings to the fore-makes present. Music and musical references help illustrate experience as both intellectual and material, ideal and perceptual, blended, changing, evolving.

One finds a very different way of referring to music and musical terms in Jean-Luc Nancy's Listening (2007). In his project, Nancy sees listening as an aesthetic or philosophical task per se. Here again, music is not in works or performances but in perception. Nancy asks:

Is listening something of which philosophy is capable? $(2007$, p. 1)

And again:

What does it mean for a being to be immersed entirely in listening, formed by listening or in listening, listening with all its being? (2007, p. 4)

[...] to listen is to be straining toward a possible meaning, and consequently one that is not immediately accessible. (2007, p. 6) 
It is, no doubt, a perceptual state - listening, a state of alertness - but it is also a situation, an experience or train of experiences that Nancy is painting. To listen is to be attentive, focused, and preoccupied with meaning and understanding more so than it is to be concerned with music. And thus far, music and musical sound only serve as an example of the object of an experience of stretching toward and getting closer to meaning, which has not been revealed yet. "To be listening is always to be on the edge of meaning, or in an edgy meaning of extremity, and as if the sound were precisely nothing else than this edge, this fringe, this margin" (Nancy, 2007, p. 7). Still, it is music, and only the experience of music, which presents the value of such intimate and focused listening. It is music and listening as conceived in reference to musical works that display the difficulty and at the same time the success of such listening. Therefore, it is also music that has to be invoked to show the true meaning of listening. As when "one tries to capture" the sonority "rather than the message" as Nancy explains (2007, p. 5).

\section{Musical Practice in Phenomenological Analysis}

A different type of phenomenology of music arises with theories presenting phenomenological analysis of musical, artistic, and aesthetic phenomena. Such theories, as those of Roman Ingarden, Mikel Dufrenne, Alfred Schütz, and Arnold Berleant, attempt at describing the special character of music and musical works in and through individual experience. Both Ingarden and Dufrenne were genuinely interested in music in its artistic forms, and music, from within its practice, was easily accessible to them. For Ingarden, musical works alongside literary works provided the best fitting and most deeply researched examples of aesthetic phenomena - the existence of which is, nonetheless, not that easily asserted in perception. They appear in the experience of musical performance or in reading literature, and they seem to vanish afterwards. Still, their social being has been assumed and prolonged due to the presence of the written score and people's memory-yet neither the material thing (the score) nor the perception of the performance seem to be the actual work of art, claims Ingarden (1986, pp. 11-12). I will not be discussing the ontological analysis for which Ingarden is most famous, however, and nor will I be interested in commenting upon his ideas about musical works as intentional objects with one strata; "on the one hand the 'fixed' relatively invariant schema, and on the other hand, the multiplicity of the possible various profiles through which a work may manifest itself” (Ingarden, 1986, p. 158). I would like to point instead to two areas of Ingarden's study relevant for understanding his phenomenological account of musical works, namely the description of aesthetic experience and the discussion of sounding and "non-sounding elements" of musical work, which show the depth of his philosophical interests in music.

Ingarden was one of the few aestheticians who took the time to discuss not the general but the specific character of aesthetic experience, describing the way in which recipients react to a work of art and what it takes to develop aesthetic experience in the first place. Ingarden's understanding of aesthetic experience is therefore both detailed and complex. Ingarden sees the experience as a process containing different phases and developing in 
different directions depending on the subject's knowledge and experience, her ability to be engaged, and her imaginative and creative powers. A musical work of art as an undetermined purely qualitative entity depends on the listener being creatively developed and qualified in the process of discovery. It should also be clear that, as Ingarden stresses, even if the experience proceeds with considerable success, it will only be fulfilled if the aesthetic object (the face of the work of art) appears as the result of both the experience and its recipient's emotional response to it, be it negative or positive, in turn allowing for the realization of aesthetic values. It is only then that the experience will be fulfilled. The process of constituting the aesthetic object and getting to know the musical work that follows has many different phases and many different avenues that it may take.

The following schema presents the general division within this process of aesthetic experience. The first (initial) phase follows from being emotionally engaged in an attempt to complete or understand a certain quality of the work as it appears before the listener. From this eagerness to complete the quality comes the first emotional response to the work, which in turns leads to a change of attitude from the practical and everyday to an aesthetic, qualitative, and engaged mode of being. What follows are many different phases of building, interpreting, and understanding of the work based upon intellectual and emotional acts of contemplating the aesthetic object that is being formed during aesthetic experience. After all these phases of completing and developing the aesthetic object comes the final phase in which the aesthetic object is finally complete and coherent and upon this aesthetic value may be realized. The values span an emotional response from the listener and hence the possibility of formulating an aesthetic judgment.

I have illustrated this bellow (see figure 1).

aesthetics mode

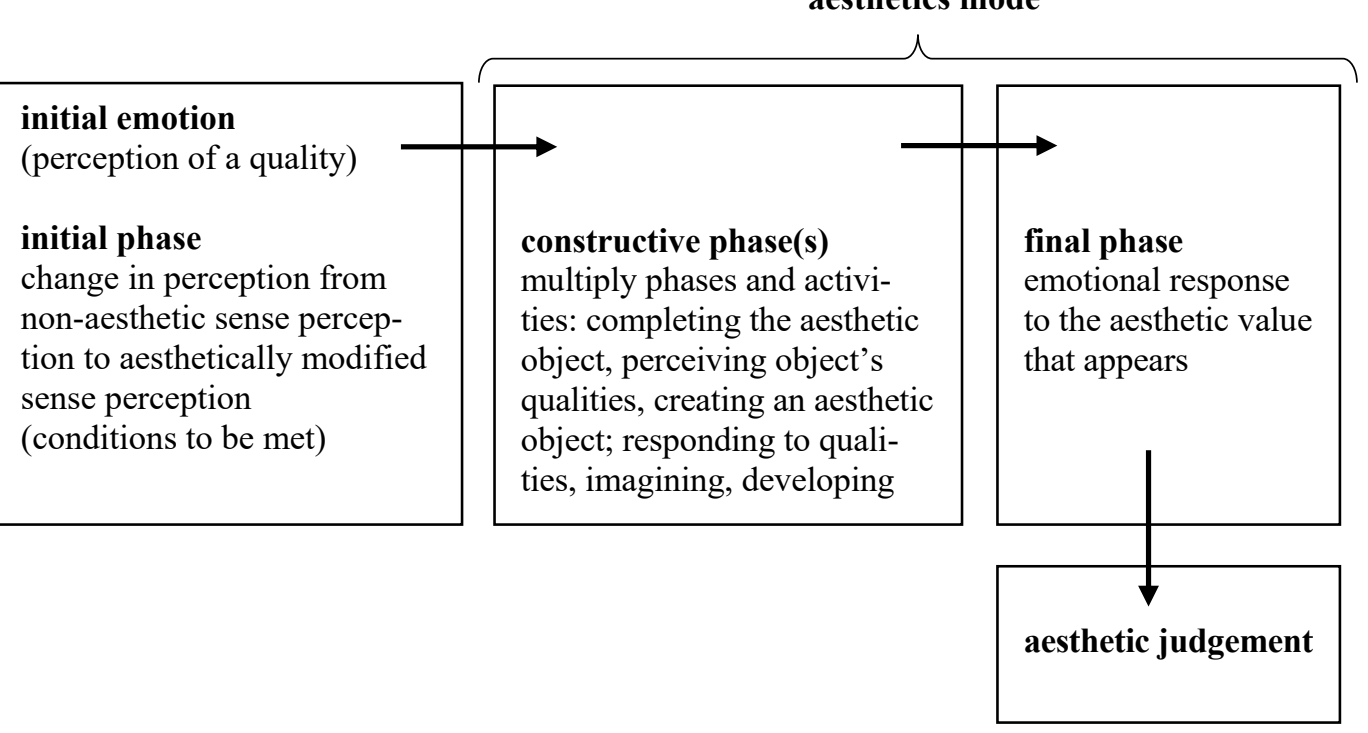

Figure 1. Ingarden's understanding of phases in aesthetic experience 
Each of these three stages of aesthetic experience usually develops into smaller phases, which are made of activities differing in mood and pace. They follow each other and often also complete each other. The more active or intellectually demanding will be followed by the more reflective or emotional ones. This way the experience develops in a wave like process in which phases are contrasted as per their intellectual content or tempo, similar to a musical process (Ingarden, 1961, p. 300).

These processes are themselves outreaching, changing, and could be presented in a more detailed schemata. Firstly, perception of a certain quality results in an emotional raise; there is a sense of curiosity and longing to know more, to perceive more of the quality that drew one in. The very emotional response to the quality-from being interested, wanting to see more and to become one with - changes one's attitude and leads her or him to the state of modified sense perception provided certain conditions are fulfilled. Then the attitude may change from neutral to aesthetic. The aesthetic attitude being one in which the primary interest is not in the state of being but in the qualitatively perceived state of the appearing. Further engagement with the quality(s) leads to a deeper sense of fulfillment in participating in the performance or during the experience of the work. However, the whole stage just described is merely a beginning, as the quality, and the work itself, requires more constructive work in order to be completed and for the experience to proceed. The next phases are constructive; even though they have both emotional and reflective parts in them, they are more about completing and constructing than the initial phase.

\section{Ingarden's understanding of phases in aesthetic experience in detail}

\section{Initial phase:}

1. perception of a certain quality, which is alluring, yet distant and which draws the recipient closer to the work;

2. preliminary emotion:

a. a sense of being in love (Eros) with the quality,

b. desire to posses/know/perceive the quality,

c. tendency to satiate oneself with this quality;

3. modified sense of perception (special conditions apply: freedom from pain, worries, mental preoccupations).

\section{Constructive phases:}

1. perceiving, recognizing, interpreting, imaginative intellectual activities;

2. completing the work's qualities, forming and developing the work's formal elements, its basic structure;

3. realizing, interpreting, harmonizing with the basic structure, developing and deepening its structure;

4. responding to features and qualities, rejoicing in those features emotionally. 
The subsequent phase - the final phase - is in Ingarden's theory perhaps the most important one. There the aesthetic experience faces completion and the aesthetic object may be verified, assessed, and evaluated. It is then and only then - as Ingarden stresses - that the perceiving subject is able to face the work of art, to "see" or "hear" it in its totalityunified and completed. It is then that one will respond to the value(s) found within he work. Finally, one may formulate one's judgment and express it verbally.

\section{Final phase:}

1. completing the aesthetic object (perceived harmony or unified quality of the object);

2. realization of aesthetic values - responding to the value with an emotional response (yes/no);

3. formulating aesthetic judgment.

I would like to point to a different part of Ingarden's phenomenology of music based on his distinction between sounding and non-sounding elements in musical works. Ingarden distinguished between sounding elements of musical works, which are physical structures and are the most widely taken to be music, and non-sounding elements of the musical work, which are not as often considered in detail. Sounding elements such as pure acoustic data (sound waves) are often considered the most important (primary) elements of musical works and musical experience, Ingarden agrees, but he claims that musical works can't be reduced to these elements. Perhaps the easiest examples are sound constructs called, simply, sounds or tones, which, despite common opinion, are not physical elements but constructs - abstract entities built upon sensory experiences. Even basic sounding elements that one hears when listening to a musical work are themselves much more complex and more difficult to identify than many realize.

Every note or acoustic product that sounds for even a brief period, and especially the performance of a musical work as a whole, possesses a multiplicity of auditory aspects enabling the listener to apprehend the given auditory product or to perform that work. These auditory aspects will vary with each listener and in successive phases of listening to the same note, melody, or chord. They would also differ within the same phase of a performance, were the listener able to hear a musical work from two different points in space. (Ingarden, 1986, p. 12)

In musical work, as Ingarden notices, there are non-sounding structures such as time organization, melodic structures, rhythmic structures, formal structures, emotional qualities, and various other qualities including aesthetically valid qualities. These elements are nonsounding elements of a musical work, but they are exeptionally important to it. In perceiving works of music, listeners often think of the basic elements of the work as sounds (and thus sounding objects), yet non-sounding elements form an equally important part of the basic structure of the musical work. In fact, phenomenological analysis of the perception of musical work seems to undermine a general understanding of music, pointing to the 
difficulty in distinguishing between simple acoustic data and the intellectual interpretive aspects of their cognition. Everything that is heard is acoustic data, but in listening to that data, as Merleau-Ponty would have it, one doesn't access the data but the intellectual content of one's act of listening. Even though it doesn't seem to be the aim of Ingarden's analysis, his questioning allows for extending and rethinking the basic plane of musical elements, pointing to complex layers of phenomenal presence rather than simple division between sounding and non-sounding elements.

Mikel Dufrenne was another author interested in music. His analysis, included in the phenomenology of aesthetic experience, pointed to musical works as exemplary of temporal arts (Dufrenne, 1953/1973). Dufrenne, similarly to Ingarden, places importance upon the differentiation between physical object (say paper with musical notation on it) and a full realization of a work of art, its full presence. Any example of music quickly brings forth the realization that music isn't present in any of its parts or preparatory stages-its presence will only be given in performance, in a full sensuous presentation. The work presents itself as $a$ "discourse in sounds," which is not meant to say something but to "exist as the interplay of sounds" (Dufrenne, 1953/1973, p. 249). The notes exercise "certain powers of attraction or repulsion" toward the other notes and assume meaning by "functioning in the whole" (Dufrenne, 1953/1973, p. 252). Dufrenne analyzes musical work in terms of harmony, rhythm, and melody, where each of those primary elements seem to differently affect the recipient but are equally interwoven into the work of music (as the three are always interconnected). Dufrenne's analysis focuses on the sensuous object of phenomenological attention and therefore the perceivable musical structure. The work of music is also further explained through the concept of sounding material. It is, however, presented from the point of view of an experiencing subject; furthermore it is assumed that the perspective is evidently different for a musician and the ordinary listener, although they both rely on the sense data for their experiences.

The musician has to do with a codified system of sounds perpetuated by a long-standing and prestigious tradition, in which the varying possibilities of timbres are themselves determined by the technique of the instrument or, as in vocal polyphony, by as many vocal possibilities as the performers offer. (Dufrenne, 1953/1973, pp. 251-252)

All those primary musical elements - harmony, rhythm, and melody - are bearers of meaning. They affect each other's presentation and are only comprehensible as parts of a whole. Their complex relationship is what makes music so special and, in effect, so deeply affective. As rhythm "participates in the total musical work, acting as its heartbeat or, better, as the secret law of its internal development. Consequently, rhythm is not reducible to the algorithm of a succession" (Dufrenne, 1953/1973, p. 257). So,

Melody is what appears spontaneously in the work when we yield to it, when we sit back and let it sing. Melody is the work itself qua duration. [...] This song, in its sovereign unfolding, is the very meaning of the musical object, a meaning that cannot be apprehended except through perception of the work. (Dufrenne, 1953/1973, p. 265) 
Thus, the understanding of music is possible only through subjective experience as the meanings of particular musical elements are revealed in relation to the one who listens. Similarly, music, as Dufrenne puts it, "unveils a world invisible to the eye, undemonstrable to the intellect. Yet this world can be expressed only by music, for it is a world which vanishes once the music ends" (1953/1973, p. 266).

Dufrenne presents a way of understanding musical works and explains musical art through thorough phenomenological analysis, but I strongly believe that it is Arnold Berleant who most successfully captures the various aspects of different performative experiences of music in his phenomenological analysis. Berleant turns to aspects of particular performances and their definitive characteristics. In this he presents not only the specific musical experience but, drawing attention to what is central in musical life, suggests that the experience of music "reveals something of a character and condition of human experience most generally" (Berleant, 1999, pp. 73-74). In writing on musical performance and its intricacies, Berleant discusses the spatial and temporal frame for individual experiences in performance. In "Notes for a Phenomenology of Performances of a Musical Work" (1999) he talks about the role of the listener in creating a shared space (a community) of the actual performance as well as the vital role of co-creative participation in it.

We are inclined to overlook the role of the listener in this process. Not only does the ear contribute materially to our auditory perception, but our attention and knowledge deeply affect what and how we hear. And what the audience offers to musical occasion ranges from its aura of attention to exclamations, clapping, singing, and applause, affecting musician and listener alike. Performance, then, is a central function in music and in some sense necessary for music to take place. (Berleant, 1999, p. 73)

Berleant argues for an engaged, participatory look at the performance rather than an objective, cold one. And just like the space of the performance, phenomenological theory is energized by the participatory and engaged account provided:

Furthermore, the space of the performance is energized by the musician. The manner in which the pianist walks to the instrument conveys a distinctive charge to the space, a temporal as well as dynamic charge. The medium thus is not purely spatial but a continuity and interpretation of space, time, and movement, the basic constituents of experiential reality. This medium becomes the condition of the singularly creative act of performance. (Berleant, 1999, p. 75)

Berleant offers a vast and intricate view of musical performance as a totality of influences and merging experiences, describing this state of flux as faithfully as possible. In the end, music, as Berleant suggests, in its "reversal of cognitive priorities" may indeed serve as a model for reconsidering various other traditional philosophical presuppositions in morality and science (1999, p. 78).

This type of phenomenology of music is, in a way, similar to philosophy of music; it addresses music as a general area of experience, a type of art and artistic practice, which is linked to a certain type of reception, certain types of goals and expectations. Such writings 
highlight the beauty and special character of music; it suggests a deeper meaning and qualities that are gained from experiences of music. It underlines the specificity of music, but at same time it gives music the highest praise. Even when, as with some philosophers, their attention is divided between different types of art, they are certain that there is something extraordinary about music, its influence on listeners, and its social impact. Ingarden claimed that music helps build a unique community, through which one is uplifted and transported and which is unlike anything else. The experience it provides is most profound. Alfred Schütz has presented music as a way of experiencing that is revealing about social reality. Debating meaning and context for that meaning in music as an artistic practice, Schütz described specific musical reality, which makes music meaningful without being referential or representational. Schutz claims that music is also unique because it doesn't [need to] refer to the world outside itself (1976, p. 244). These types of writings about music are phenomenological in the sense that they employ the phenomenological methods of following experience in order to know the subjective reality of responding to (or creating) music as well as, in many cases, attempts to perform eidetic reduction. But there is yet another type of phenomenology of music, which is based on an even more in-depth experiencing and understanding of the inner self through the experience of sound and sounding. This could perhaps be called a phenomenology of listening.

\section{Back to Listening}

The phenomenology of music starts with sound and ends with sound. But the experience that is involved in responding to music, as much as with other sounding phenomena, is an auditory experience, less and more than sound, or else a different experience all together. In the studies of auditory experiences, listening is a discovery and description of everyday experience as well as standing for a specifically phenomenological approach to the world, and yet it is the most specific and transparent but complex aspect of music. In Don Ihde's Phenomenologies of Sound (2007) this area of human experience is called auditory imagination. The focus is on listening, attending, and interpreting imaginatively. Nevertheless, it is music and the experience of music that most effectively allows for such development and stretching of the everyday experience of sound into meaningful audio perception. "All the sound, we noted, is the field which might be called the field of possibilities for music, even as anything might be an instrument, and all voices primordial musical statements" (Ihde, 2007, p. 202).

This deep, soft listening is based on imagination and anticipation (quite different from listening for footprints or whispers of danger). It is an acousmatic experience, a listening for possibilities and for qualities. And in this sense music is not only an inspiration but a paradigmatic experience of this type. However, even here, the experience of listening, both during a musical performance and in anticipation of one, the phenomenology of listening points to describing appearances and phenomena; it guides attention to discovering the how, the quality_-just like in the phenomenological musing of Jean-Luc Nancy. Listening 
is meant as a way of interpreting an experience, which is telling and yet completely enclosed in itself, meaningful and yet so secretive that it is almost mute. In some strange way, music is truly inspirational for all that philosophical exploration. The musical qualitative experience based on listening and attentive imagination is what makes it all applicable to so many things. As an experience different and unique, the sonorous as arriving in opposition to visual presence that is already there (Nancy, 2007, p. 14).

\section{Conclusion}

There are many different areas of music and musical experience that have been taken up in phenomenology and phenomenological studies of music. One might say that phenomenology of music starts with audible phenomena that create and shapes the listening space and then proceed to include all the individual perspectives of particular listeners. Therefore, while phenomenology is often accepted as the general perspective for the listening experience, it is most promising to undertake phenomenological studies of music from the perspective of everyday happenings and the discoveries of musical aspects of everyday life. Doing so facilitates hoping that music, or what we take to be music, can illuminate these everyday experiences and influence perception. Perhaps that is what music truly is, not only perception but affective changes in perception, and therefore phenomenology of music should make studying this its primary task.

\section{References}

Berleant, A. (1999). Notes for phenomenology of musical performance. Philosophy of Music Education Review, 7(2), 73-79.

Dufrenne, M. (1973). The phenomenology of aesthetic experience (E. S. Casey, Trans.). Evanston, IL: Northwestern University Press. (Original work published 1953)

Heidegger, M. (1962). Being and time (J. Macquarrie \& E. Robinson, Trans.). Oxford, UK: Blackwell Publishing. (Original work published 1927)

Husserl, E. (1964/1991). The lectures on phenomenology of internal time consciousness (J. Brough, Trans.). Dordrecht, the Netherlands: Springer.

Ihde, D. (2007). Listening and voice: Phenomenologies of sound. Albany, NY: State University of New York Press.

Ingarden, R. (1961). Aesthetic Experience and Aesthetic Object. Philosophy and Phenomenological Research, 21(3), 289-313.

Ingarden, R. (1986). The work of music and the problem of its identity (A. Czerniawski, Trans.). Houndmills, UK: The Macmillan Press Ltd.

Merleau-Ponty, M. (1964). Phenomenology and the sciences of man (J. Wild, Trans.). In J. M. Edie (Ed.), The primacy of perception (pp. 43-95). Evanston, IL: Northwestern University Press. 
Merleau-Ponty, M. (1967). The structure of behavior (A. I. Fisher, Trans.). Boston, MA: Beacon Press. (Original work published 1942)

Merleau-Ponty, M. (2004). The world of perception (O. Davis, Trans.). New York, NY: Routledge. (Original work published 1948)

Merleau-Ponty, M. (2012). Phenomenology of perception (D. A. Landes, Trans.). London, UK: Routledge. (Original work published 1945)

Nancy, J.-L. (2007). Listening (C. Mandell, Trans.). New York, NY: Fordham University Press.

Schütz, A. (1996). Fragments toward a phenomenology of music. Appendix, In H. Wagner and G. Psathas (Eds.), Collected Papers (Vol. IV, pp. 243-275). Dordrecht, Boston, London: Kluwer Academic Publishers

Wiskus, J. (2013). The rhythm of thought: Art, literature, and music after Merleau-Ponty. Chicago, IL: University of Chicago Press.

Wrathall, M. (2011). The phenomenological relevance of art. In J. D. Parry (Ed.), Art and phenomenology (pp. 9-10). London, UK: Routledge. 